Conclusion This study demonstrated the importance of promoting visits to an OP before returning to work. In the future, OHS could facilitate return to work by supporting companies in implementing sick-leave policy. Contacting workers on sick leave and offering opportunities for visits prior to return to work could create added value for employees and employers.

\section{SUCCESSFULLY IMPLEMENTING INFORMATION SYSTEMS TO IMPROVE OCCUPATIONAL HEALTH AND SAFETY PERFORMANCE - 1: CHALLENGES AND OPPORTUNITIES}

${ }^{1} \mathrm{JM}$ Spiegel ${ }^{*},{ }^{2,3} \mathrm{D}$ Jones, ${ }^{2,3,4} \mathrm{~L}$ Darwin, ${ }^{1} \mathrm{P}$ Adu, ${ }^{1} \mathrm{~A}$ Yassi. ${ }^{1} \mathrm{Global}$ Health Research Program, School of Population and Public Health, University of British Columbia, Vancouver, Canada; ${ }^{2}$ National Health Laboratory Service (NHLS), Johannesburg, South Africa; ${ }^{3}$ National Institute for Occupational Health, NHLS, Johannesburg, South Africa; ${ }^{4}$ National Institute for Communicable Diseases, NHLS, Johannesburg, South Africa

\subsection{6/oemed-2018-ICOHabstracts.521}

Introduction Although information systems (IS) have been widely applied to address health concerns worldwide, few initiatives address workers health and safety. This is especially the case in the health sector, an area the High Level Commission on Health Employment and Economic Growth acknowledged to be in need of attention, particularly in low and middle-income countries.

Methods Applying a context-mechanism-outcome study design, we analyse how a comprehensive IS initially introduced in Canada was successfully transferred to South Africa (SA) through a partnership of two WHO Collaborating Centres in Occupational Health and Safety. We particularly explore contextual (socio-political and technological) characteristics at micro, meso and macro levels and the processes applied have affected outcomes.

Results Despite limited success in initial piloting in a resource stressed provincial health department, a technology transfer partnership relying on SA technical IS core capacities and management commitment to maintain systems enabled successful application of OHASIS (Occupational Health and Safety Information System) through South Africa's National Health Laboratory Service. Success has been observed through patterns of use (incident investigation, hazard assessment, workforce health) of the system and the development of new modules to meet additional management needs (e.g. waste management, audits). Application of OHASIS is presently being scaled up in the Gauteng province health sector and in Namibia, with considerable additional interest in wider application being expressed.

Discussion The efficacy of technical systems to enable surveillance of health and safety consequences for workers together with consideration of the workplace factors and processes that affect this is necessary but not sufficient for success. Documentation of how the system is implemented (possible through analysis of the analytics of use) as well as how analysis of evidence can enable ongoing research and management improvement is critical to ensuring that commitments are maintained and the reports needed by users are made available.
861 SUCCESSFULLY IMPLEMENTING INFORMATION SYSTEMS TO IMPROVE OCCUPATIONAL HEALTH AND SAFETY PERFORMANCE - 2: CASE STUDIES

${ }^{1,2}$ D Jones* ${ }^{*}$ 1,3 L Darwin, ${ }^{1,2} \mathrm{~K}$ Wilson, ${ }^{1,2} \mathrm{~S}$ Kisting, ${ }^{3,4} \mathrm{JM}$ Spiegel, ${ }^{3,4} \mathrm{P}$ Adu, ${ }^{3,4} \mathrm{~A}$ Yassi. ${ }^{1}$ National Health Laboratory Service, Johannesburg, South Africa; ${ }^{2}$ National Institute for Occupational Health, Johannesburg, South Africa; ${ }^{3}$ National Institute for Communicable Diseases, NHLS, Johannesburg, South Africa; ${ }^{4}$ Global Health Research Program, School of Population and Public Health, University of British Columbia, Vancouver, Canada

\subsection{6/oemed-2018-ICOHabstracts.522}

Introduction With over 7400 employees in 346 laboratories and 3 national institutes across South Africa, the National Health Laboratory Service (NHLS) faces the challenge of how to provide occupational health, biosafety and biosecurity services with limited resources. The Occupational Health and Safety Information System (OHASIS) was initially developed at the University of British Columbia in Canada as a multi-modular, secure online information system and is now a joint venture with South Africa's National Institute for Occupational Health.

Methods By reviewing 6 years of OHASIS and health and safety program implementation at NHLS, including surveying of users, we provide a qualitative and quantitative summary of experience, including presentation of illustrative cases, and discuss the strengths and limitations of using a comprehensive information system to improve occupational health and safety.

Results Online surveys (2013 and 2015) indicated an overall improvement in many areas of health, biosafety and biosecurity including training, trust of management, reporting incidents, use of Personal Protective Equipment and participation in committees. Over 1600 incidents have been recorded, with increased usage following introduction of a confidential selfreport mechanism. This has enabled systematised reviews by health and safety committees, the Safety, Health and Environment team and NHLS management. In addition to existing modules (e.g. incident reporting and investigation; employee health; analytics), new modules have been added in response to user requests: Audits; Waste; Maintenance; and Training. A strategic new module on Health and Safety Committees is currently underway.

Discussion Surveys and discussions reveal a need for ongoing attention to implementation. Analysis of trends and associations is being emphasised as long term sustainability solutions are being sought, especially in response to the widespread interest for introducing OHASIS in other settings. The National Institute for Occupational Health has the exclusive rights to roll OHASIS out throughout Africa.

\section{EXPLORING KEY INFORMANT PERCEPTIONS REGARDING THE PREVENTION AND CONTROL OF TUBERCULOSIS AMONG HEALTHCARE WORKERS}

${ }^{1} \mathrm{PA} \mathrm{Adu}$ *, ${ }^{1} \mathrm{~A}$ Yassi, ${ }^{2} \mathrm{R}$ Ehrlich, ${ }^{1} \mathrm{JM}$ Spiegel. 'School of Population and Public Health, University of British Columbia, Vancouver, Canada; ${ }^{2}$ School of Public Health and Family Medicine, University of Cape Town

10.1136/oemed-2018-ICOHabstracts.523 
Introduction A particular sub-population known to be at high risk of tuberculosis (TB) infection is health workers, with rates of infection estimated at 2-5 times that of the general population. Evidence indicates that Infection control practices are poorly implemented. The objective of this study was to investigate perceptions of knowledgeable informants regarding the macro level drivers of $\mathrm{TB}$ infection in the healthcare setting and explore their perceptions of barriers as well as actions that could enhance the capacities to prevent and control TB infection among HCW.

Methods This qualitative study involved semi structured interviews with 18 stakeholders working in occupational health and TB management in South Africa. These included 10 government authorities with responsibility for TB control, 4 academic experts, 2 TB advocacy group members, a legislator, and a hospital CEO. Interviews were audio recorded and transcribed verbatim, validated and analysed aided by Nvivo 11 qualitative data management software.

Results Perceptions of the major drivers of occupationallyacquired TB that emerged from the key informant interviews included: the high incidence in the general population, budgetary constraints in healthcare system allocation, inadequate human resources dedicated to occupational health $(\mathrm{OH})$, poor implementation culture, the nature of governance of $\mathrm{OH}$ related issues, lack of priority for $\mathrm{OH}$, and other socio-cultural factors. Improvement in the governance of TB related issues, priority setting and implementation and adherence to occupational health and safety policies were identified as crucial to improving TB prevention and control strategies

Discussion Occupational health and safety is seen as lacking in priority in the healthcare system. Although a national TB policy for HCWs will soon be launched, it is perceived that implementation and adherence to such policies remain problematic due to a chronic underfunding of the health sector in general.

\section{ACTIVITY OF DOKTOR24 COMPANY GROUP, CLOSE COOPERATION OF OCCUPATIONAL HEALTH,OSH, PREVENTION. PRESENTATION OF GOOD PRACTICE FROM LARGE PROVIDER IN HUNGARY}

Éva Ruzsás, Barnabas Biró, Antal Sándor Nikl. Doktor24 - Medicina B.M. Ltd, Budapest, Hungary

\subsection{6/oemed-2018-ICOHabstracts.524}

Presentation of the legal environment in Hungary:

- Cancun Charter, ICOH National Secretariat and the role of ICOH Hungarian National Secretariat in the survival of occupational health in Hungary

- statistics

- Introduction of Doktor24 company group - Professionally diverse tasks, closed and open clinics, maior central clinic

- Close relationship between occupational health and work safety - Mandatory flow of information on labour accidents

- First aid training - vocation

- Rapid growth of the role of labour psychologist

- Prevention programs - Their public health significance due to mandatory occupational health examinations

- Weight control program
- Bodywakes Lifestyle Consultant Program

- Smoking cessation intervention programme

- Cardiovascular screening

- Melanoma screening

- Promotion of the need for regular exercise - Fitness room operation

\section{PREVENTION OF COMMON MENTAL DISORDERS IN EMPLOYEES - ATTITUDES OF HEALTH CARE PROFESSIONALS, HUMAN RESOURCES MANAGERS, AND EMPLOYEES IN GERMANY}

${ }^{1} \mathrm{MA}$ Rieger*, 'S Burgess, ${ }^{2} \mathrm{~F}$ Junne, ${ }^{3} \mathrm{E}$ Rothermund, ${ }^{3} \mathrm{H}$ Gündel, ${ }^{2} \mathrm{~S}$ Zipfel, ${ }^{1,4} \mathrm{M}$ Michaelis. ${ }^{1}$ Institute of Occupational and Social Medicine and Health Services Research, Tübingen, Germany; ${ }^{2}$ Department of Psychosomatic Medicine and Psychotherapy, University Hospital Tübingen, Germany; ${ }^{3}$ Department of Psychosomatic Medicine and Psychotherapy, University Hospital Ulm, Germany; ${ }^{4}$ Freiburg Research Centre for Occupational and Social Medicine, Freiburg, Germany

\subsection{6/oemed-2018-ICOHabstracts.525}

Introduction Many studies investigate the possible positive and negative effects of work-related factors on mental health of employees, but only little is known about the attitudes of the persons involved. Therefore we aimed to assess the perceptions of occupational health physicians (OHP), primary care physicians (PCP), psychotherapists (PT), human resources managers (HRM), and employees (EMP) with regard to workrelated risk factors and possibilities for prevention of common mental disorders (CMD) at the workplace.

Methods A standardised questionnaire was developed to assess the individuals' attitudes with regard to different aspects of prevention of CMD in employees. The survey assessing the estimates concerning work-related and individual risk factors, cooperation of persons involved, and engagement of specific institutions first was developed for a postal survey among OHPs, PCPs, PTs, and HRMs in 2014. ${ }^{1}$ Second, the content was slightly adapted to perform an online survey among employees addressing an online access panel in 2016. Besides descriptive measures or explorative bivariate methods, multivariate logistic regression analysis with IBM SPSS 22 was computed.

Results Data were gathered from 133 OHPs (response rate 30\%), 136 PCPs (14\%), 186 PTs (27\%), 172 HRMs (12\%) and 610 EMPs (stipulated number of participants). The significance of several work-related factors (e.g. work-related demands, work organisation) for the development of CMD in employees was judged rather similarly by the health professionals but lower by HRM. The employees' perception often led between both. Individual predisposition for CMD was rated less important by HRM and EMP than by health professionals. The potential of work-related aspects for prevention of CMD was assess similarly high by health professionals and EMP, but slightly lower by HRM.

Discussion The multiperspective survey revealed different answering patterns of the five groups indicating possibilities as well as need for further actions with regard to work-related prevention of CMD in employees.

\section{REFERENCE}

1. Michaelis, et al. Mental Health \& Prevention 2016;4:88-95. 